\title{
An fMRI Investigation on Brain Activity in Response to Unilateral Acupuncture, Electroacupuncture and Electromyostimulation on ST36 and ST39
}

\author{
Li-Ping Huang et al.* \\ Tianjin University of Sport \\ China
}

\section{Introduction}

It is known that unilateral resistance exercise training may result in an increased muscular strength not only in the exercised muscle, but also in the unexercised homologous muscle in the contralateral limb. This phenomenon is termed cross education. Cross-education effect has been shown in hand, arm and leg muscles after various types of resistance training (Farthing, 2009; Hortobagyi, 2005; Lee \& Carroll, 2007; Lee et al., 2010; Munn et al., 2004; Zhou, 2000). Furthermore, it has been reported that repeated unilateral transcutaneous electrical stimulation on a limb muscle or a nerve trunk may also cause cross-education effect (Bezerra et al., 2009; Cabric \& Appell, 1987; Hortobagyi et al., 1999; Singer, 1986; Tachino et al., 1989; Zhou et al., 2002). Although the magnitude of strength gain in the contralateral limb is generally less than that in the exercised limb, this cross-over effect might have clinical values in neuromuscular rehabilitation (Farthing et al., 2009; Singer, 1986; Woo et al., 2006).

More interestingly, unilateral therapy for treatment of conditions on the contralateral side of the body has been used in traditional Chinese medicine for centuries (Kim et al., 2010; Woo et al., 2006). One particular type of treatment, juci, involves acupuncture on one side of the body to affect the function of the other side (Lin \& Pan, 2004). This appears to be similar to the concept of cross education. A recent investigation in our laboratory has demonstrated that four weeks of electroacupuncture on tibialis anterior muscle (TA) of one limb can significantly increase dorsiflexion muscle strength in both the stimulated limb and the contralateral limb (Huang et al., 2007).

The exact mechanism of cross education is not clear. In principle, muscle strength can improve in adaptation to voluntary exercise training due to either or both an improved neural control and/or muscle hypertrophy. Because there has been little evidence of a significant muscle hypertrophy associated with improved strength in the contralateral limb,

\footnotetext{
* Shi Zhou ${ }^{2}$, Xi-Lian Hu${ }^{1}$, Xia Li ${ }^{1}$, Heng Xiang ${ }^{1}$, Na Xiao' ${ }^{1}$, Long-Jun Cao' ${ }^{1}$, Yong-Jun Wang ${ }^{1}$ and Hui Wang1

${ }^{1}$ Tianjin University of Sport, China

${ }^{2}$ Southern Cross University, Australia
} 
it is believed that cross education is primarily caused by adaptations in the central nervous system (Bezerra et al., 2009; Dragert \& Zehr, 2011; Everaert et al., 2010). Several candidate mechanisms have been proposed in the literature, including ipsilateral innervation to the muscle due to a small proportion of uncrossed nerve fibres in the corticospinal pathway; bilateral activation of muscles for maintenance of posture during a unilateral exercise; and bilateral interaction between the two hemispheres of the brain (Carroll et al., 2006; Farthing, 2009; Hortobágyi et al., 2011; Zhou, 2000). However, the neural mechanisms for the cross education induced by electric stimulation or electroacupuncture may not be the same as that induced by voluntary exercise because the stimulation is applied to a peripheral nerve or muscle that by-passes the corticospinal pathway. It has been speculated that the sensory afferents may play an essential role in mediating cross-education effect induced by electric stimulation and electroacupuncture (Hortobagyi, 2005; Huang et al., 2007). Furthermore, whether the cross-education effect caused by electrical stimulation on surface or via needling at the acupoint involves similar or different neural mechanisms has not been examined.

The research presented in this Chapter utilised the functional magnetic resonance imaging (fMRI) technique to examine the brain activities during unilateral electric stimulation and acupuncture. The technique of fMRI is based on detection of blood oxygenation level dependent (BOLD) signals that provides a direct and precise indication of the regions in the brain involved in a given sensory-motor task.

The aim of the present study was to compare the areas of the brain that were activated, as indicated by $\mathrm{fMRI}$, during unilateral transcutaneous electrostmulation, manual acupuncture and electroacupuncture on the acupoints of ST36 (Zusanli) and ST39 (Xiajuxu) in healthy young adults, in order to obtain a better understanding of the differences in the areas activated during these tasks and how these might contribute to the mechanisms of cross education or unilateral therapy. It was hypothesised that electroacupuncture on acupoints and transcutaneous electric stimulation on the same areas of the tibialis anterior muscle would induce similar level of activities in certain regions of the contralateral and ipsilateral side of the brain; and manual acupuncture at the same acupoints may also cause activation of the same regions in the brain, but to a less magnitude, as indicated by the BOLD signals.

\section{Methods}

Six healthy young men with a mean age of 23 years (range 21-26 years) volunteered for the study. All participants were right-foot dominant as identified using an established questionnaire (Li, 1983) and without current neuromuscular, orthopedic, diabetes mellitus and cardiovascular diseases or neuromuscular injuries. Participants were physically active, without a history of specific sport training, especially muscle strength training, during the six months prior to the study, and had no previous experience with acupuncture or electric stimulation. They did not show a fear to acupuncture and electric stimulation. All participants gave their consent to participation prior to the experiment. The experiment was carried out in accord with the Declaration of Helsinki, and the procedure obtained approval by the Human Research Ethics Committee of Southern Cross University, Australia.

One week prior to the formal experiment, each participant was given two familiarisation trials, one in the University's laboratory and the other in the MRI room at the hospital. During the familiarisation trials the detailed experimental procedure was explained to the participants. The participants were given transcutaneous electric stimulation, manual acupuncture and 
electroacupuncture at the acupoints ST36 and ST39 of the right leg, respectively. The stimulation intensity was increased gradually till the level that the participant could maximally tolerate. A post-hoc investigation $(n=5)$ found that the electromyogram (EMG) activity of the left anterior tibialis muscle showed no significant changes ( $P>0.05$ by ANOVA with repeated measures) between resting and when the right leg received electric stimulation (contraction intensity was up to $40 \%$ maximal voluntary contraction, $\mathrm{MVC}$, at the maximum tolerance), electroacupuncture (up to $30 \% \mathrm{MVC}$ ) or manual acupuncture (up to $10 \% \mathrm{MVC}$ ). The EMG activity of the left anterior tibialis during the stimulation or acupuncture on the right leg was generally below $1.5 \%$ of that during a maximal voluntary contraction.

During the experimental trial for fMRI scanning, participant was in a supine position, relaxed and with eyes closed. The head position in the head coil was stabilised by foam padding. The right leg of the subject was strapped into a custom-built device at the thigh and foot with the knee joint angle at 0 degrees and the ankle joint at 15 degrees in plantar flexion. The left leg was in full extension and the participant was told to relax the muscles.

The experiment included three tasks with block-design to detect BOLD signals. The tasks were performed in the order of transcutaneous electric stimulation, manual acupuncture and electroacupuncture on the ST36 and ST39 of the right leg. In each task, there was three sets of 1 min rest (reference period) followed by 1 min stimulation or acupuncture. A minimum of 10 minutes rest was given between the tasks.

The location of the acupoints ST36 and ST39 were determined according to the description of traditional Chinese medicine (Beijing College of Traditional Chinese Medicine et al., 1980) by an accredited acupuncturist who had been practicing in hospital for 10 years. The ST36 is located at 3 cun distance (cun is a unit of length relative to patient's body size in traditional Chinese medicine. Three cun is the breadth of the patient's index, middle, ring, and little fingers at the level of proximal interphalangeal joint at the dorsum of the middle finger) from the depression below the patella and lateral to the patellar ligament, and one finger breadth lateral to the anterior crest of the tibia. The ST39 is located at 9 cun distance from the depression below the patella and lateral to the patellar ligament and one finger breadth lateral to the anterior crest of the tibia (Figure 1).

During the surface electric stimulation task, the stimulation was applied to the tibialis anterior muscle via a Trio300 stimulator (ITO, Japan). Two $5 \mathrm{~cm} \times 5 \mathrm{~cm}$ self-adhesive MRIcompatible electrodes (ITO, Japan) were placed over the muscle with the cathode on ST36 and the anode on ST39. The stimulator was located outside of the MRI room and linked to the electrodes via MRI-compatible wires. The stimulation was delivered at a duty cycle of 5 $\mathrm{s}$ rest followed by $5 \mathrm{~s}$ stimulation, 6 cycles per set (a total of 1 minute). The electrical pulses were square waves at $50 \mathrm{~Hz}$, with the pulse width of $200 \mu$ s and intensity of $48-55 \mathrm{~mA}$ according to the level that the participant could maximally tolerate in the familiarisation trials.

During the manual acupuncture task, a pure silver acupuncture needle with diameter of $0.3 \mathrm{~mm}$ and length of $50 \mathrm{~mm}$ (GB2024-94, Suzhou Medical Appliance Company, Ltd., China) was inserted vertically into the muscle at each acupoint to a depth of 20 to $30 \mathrm{~mm}$ by the accredited acupuncturist. The needles were manually twirled at $1 \mathrm{~Hz}$ to induce a feeling of de qi. The de qi sensation is a combination of aching, pressure, soreness, heaviness, fullness, warmth, cooling, numbness, tingling, and dull pain, but not a sharp pain (Hui et al., 2007). The acupuncture was applied for $60 \mathrm{~s}$ after $60 \mathrm{~s}$ rest in each set. Three sets were performed. 


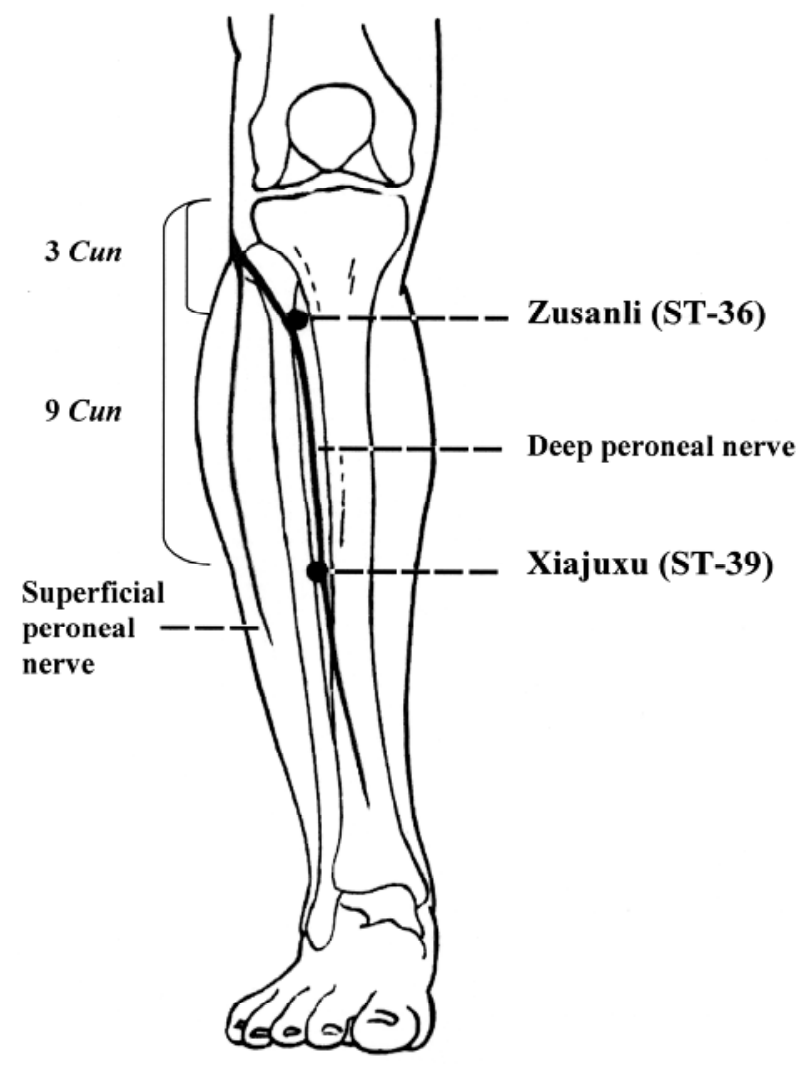

Fig. 1. Location of the acupoints ST36 and ST39 [Figure from Huang et al. (2007). Journal of Alternative and Complementary Medicine, 13(5), 539-546, with permission].

The protocol of electroacupuncture task was similar to that of electric stimulation, with the surface electrodes replaced by acupuncture needles inserted into the muscle at the acupoints. The electrical pulses were delivered to the needles by using an electroacupuncture apparatus (SDZ-II, Suzhou Medical Appliance Company, Ltd., China), with square waves at $50 \mathrm{~Hz}$, pulse width of $200 \mu$ s and intensity of 8 to $11 \mathrm{~mA}$ which was the maximal level that the participant could tolerate in the familiarisation trials.

A $1.5 \mathrm{~T}$ whole body MRI scanner (GE, 1.5 T twin speed infinity with Excite II, USA) was used for fluid attenuation inverse recovery T1-weighted imaging (FLAIR T1WI) and gradient echo-echo planar imaging (GRE-EPI) fMRI scanning. Anatomical images were acquired with a repetition time (TR) of $2250 \mathrm{~ms}$, a time for echo (TE) of $11.6 \mathrm{~ms}$, a time for inversion of $760 \mathrm{~ms}$, bandwidth (BH) $19.32 \mathrm{KHz}$, field of vision (FOV) $24 \mathrm{~cm} \mathrm{x} 18 \mathrm{~cm}$, data matrix $320 \times 224$, slice thickness $6 \mathrm{~mm}$ with $1 \mathrm{~mm}$ gap, for 20 slices that covered the distance from the apex of the scull to the lower edge of the cerebellum. The fMRI used the GRE-EPI technique with parameters of TR $3000 \mathrm{~ms}$, TE $40 \mathrm{~ms}$, flip angle 90 degrees, BH $62.50 \mathrm{KHz}$, FOV $24 \mathrm{~cm} \times 24 \mathrm{~cm}$, data matrix $128 \times 128$ for an in-plane resolution of $1.875 \mathrm{~mm} \times 1.875$ 
mm. Slice thickness $6 \mathrm{~mm}$, gap $1 \mathrm{~mm}$, with 20 slices that corresponded to the T1WI. Three scans with a total scanning time of 7 minutes were performed for each task.

The fMRI signals were monitored by a real time imaging processor. If participant's head position moved for more than $5 \mathrm{~mm}$, the scan would stop automatically. The participants in this study cooperated well and there was no case of significant head movement that required repositioning. The original fMRI data in DICOM format was transferred to a computer where the statistics parameter mapping software was used for analysis (SPM99, Wellcome Department of Imaging Neuroscience, University College London, UK). Conjunction analysis was performed to compare the fMRI signals among the three tasks. The activation of the areas in the brain was estimated by correlative analysis for temporal-signal intensity curve with stimulation. The threshold for identifying an active area was set as 10 voxels. The fMRI image analysis was performed by a medical imaging specialist. Paired $t$-test was used to identify task-related activities as compared to the resting period, with the Alpha level of 0.005 was used for significant differences (uncorrected) (Bai et al., 2009).

\section{Results}

All fMRI trials were completed successfully. During the transcutaneous electric stimulation task, significant activation $(\mathrm{p}<0.005)$ was detected in the areas of bilateral gyrus postcentralis (GOPC, Brodmann area [BA]43), lobulus parietalis inferior (LPi, BA40), gyrus frontalis medius (GFm, BA8,10), inferior temporal gyrus (GTi, BA37), gyrus temporalis superior (GTs, BA38,42) and brain stem; ipsilateral gyrus frontalis superior (GFs, BA6), insula (INS) and hippocampus (HI); and contralateral gyrus frontalis medialis (GFd, BA6), gyrus cinguli (GC, BA24), nucleus lentiformis (NL), lobulus paracentralis (LPC, BA5,7), gyrus precentralis (GPRC, BA4), cerebellum (Cb) and internal capsule (IC) (Table 1, Figure 2).

\begin{tabular}{lccccccccc}
\hline Activated & Brodmann & \multicolumn{3}{c}{ Contralateral $(\mathrm{mm})$} & \multicolumn{2}{c}{ T value } & \multicolumn{4}{c}{ Ipsilateral $(\mathrm{mm})$} & T value \\
Area & & $\mathrm{x}$ & $\mathrm{y}$ & $\mathrm{z}$ & & $\mathrm{x}$ & $\mathrm{y}$ & $\mathrm{z}$ & \\
\hline GPOC & 43 & -57 & -21 & 15 & 14.63 & 45 & -39 & 63 & 22.38 \\
LPi & 40 & -60 & -39 & 24 & 9.4 & 51 & -30 & 27 & 21.70 \\
GTi & 37 & -63 & -54 & -9 & 13.17 & 60 & -60 & -12 & 31.78 \\
GTs & 38,42 & -66 & -24 & 12 & 8.12 & 63 & -12 & 9 & 14.07 \\
GFm & 8,10 & -36 & 60 & 12 & 9.00 & 39 & 12 & 48 & 14.14 \\
Brainstem & $/$ & -6 & -21 & -9 & 9.61 & 15 & -30 & -39 & 11.59 \\
INS & $/$ & $/$ & $/$ & $/$ & $/$ & 39 & -9 & -12 & 15.09 \\
HI & $/$ & $/$ & $/$ & $/$ & $/$ & 30 & -18 & -9 & 8.13 \\
GFS & 6 & $/$ & $/$ & $/$ & $/$ & 9 & 9 & 63 & 10.82 \\
GFd & 6 & -3 & -21 & 63 & 12.47 & $/$ & $/$ & $/$ & $/$ \\
GC & 24 & -3 & -6 & 33 & 10.10 & $/$ & $/$ & $/$ & $/$ \\
NL & $/$ & -18 & 6 & 6 & 15.70 & $/$ & $/$ & $/$ & $/$ \\
LPC & 5 & -6 & -33 & 63 & 16.86 & $/$ & $/$ & $/$ & $/$ \\
GPRC & 4 & -33 & -6 & 36 & 9.73 & $/$ & $/$ & $/$ & $/$ \\
Cb & $/$ & -15 & -66 & -33 & 9.58 & $/$ & $/$ & $/$ & $/$ \\
IC & $/$ & -15 & 0 & 15 & 12.54 & $/$ & $/$ & $/$ & $/$ \\
\hline
\end{tabular}

Table 1. Montreal Neurology Institute (MNI) coordinates of local maxima of cortical clusters showing significant $(\mathrm{P}<0.005)$ activity associated with transcutaneous electric stimulation at the acupoints of ST36 and ST39 in the right leg. 


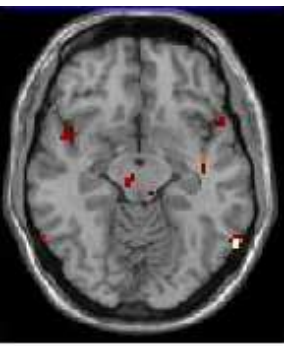

$Z=-12$

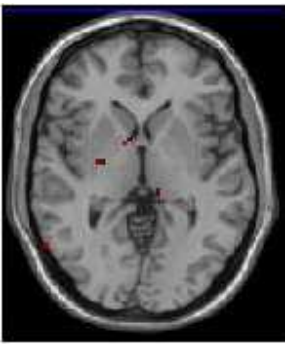

$\mathrm{Z}=0$

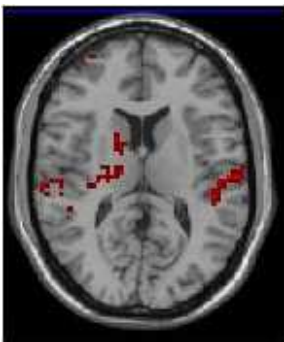

$\mathrm{Z}=12$

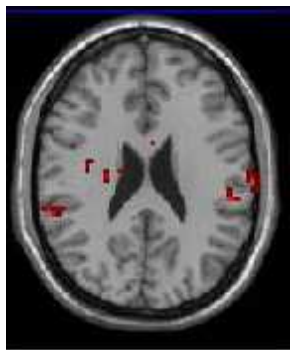

$Z=24$

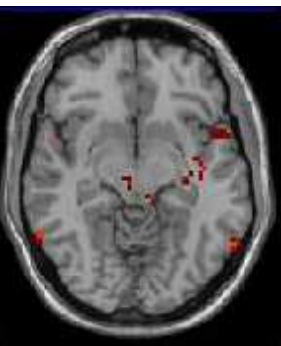

$Z=-9$

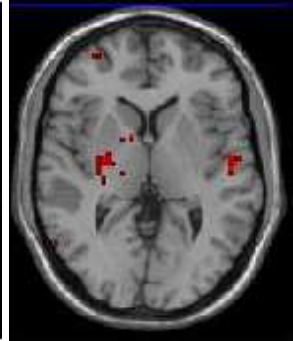

$Z=3$

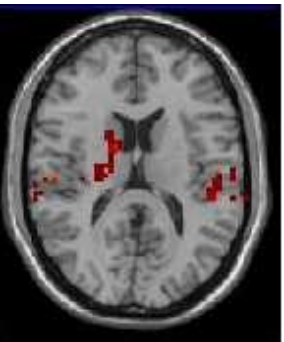

$Z=15$

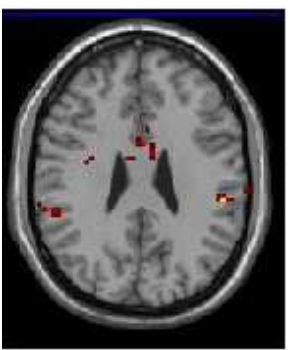

$Z=27$

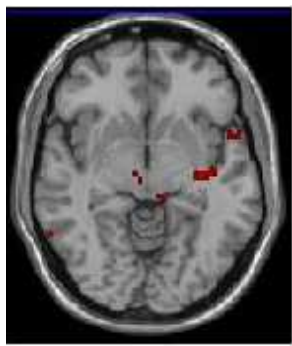

$Z=-6$

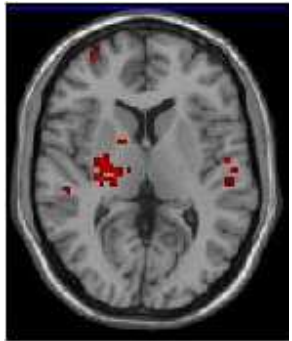

$Z=6$

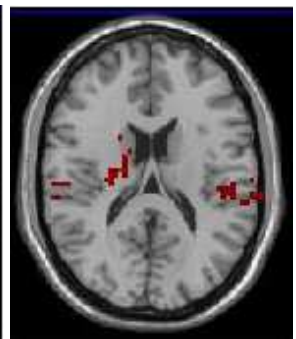

$\mathrm{Z}=18$

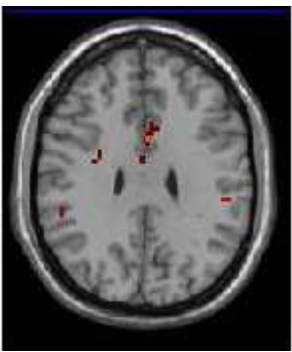

$Z=30$

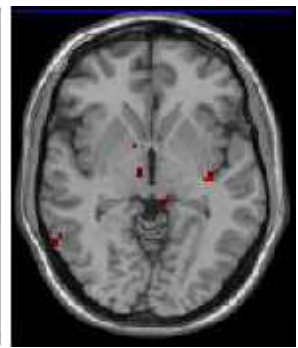

$Z=-3$

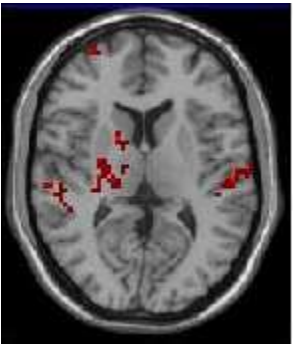

$Z=9$

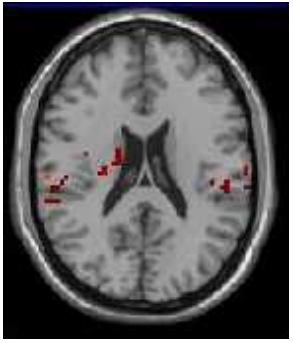

$\mathrm{Z}=21$

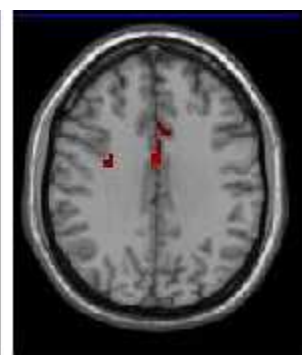

$Z=33$

(Figure 2) 
An fMRI Investigation on Brain Activity in Response to Unilateral Acupuncture,
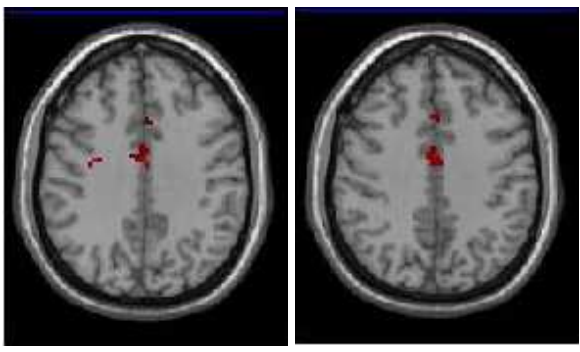

$Z=36$

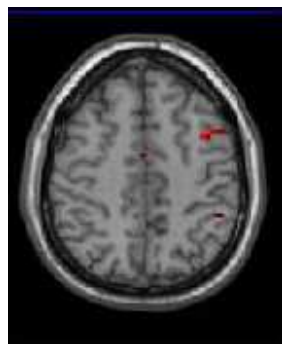

$Z=48$
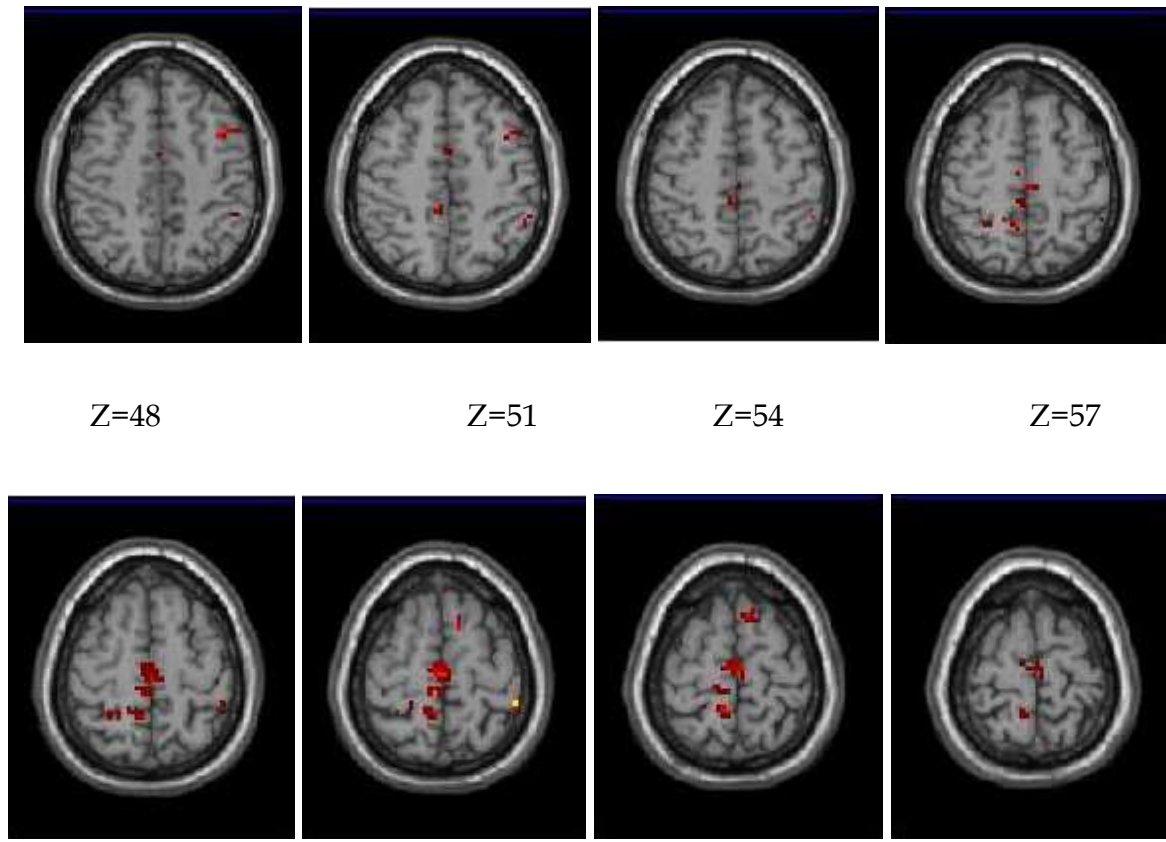

$Z=60$

$Z=63$

$Z=66$

$Z=69$

(Figure 2 continuing) 


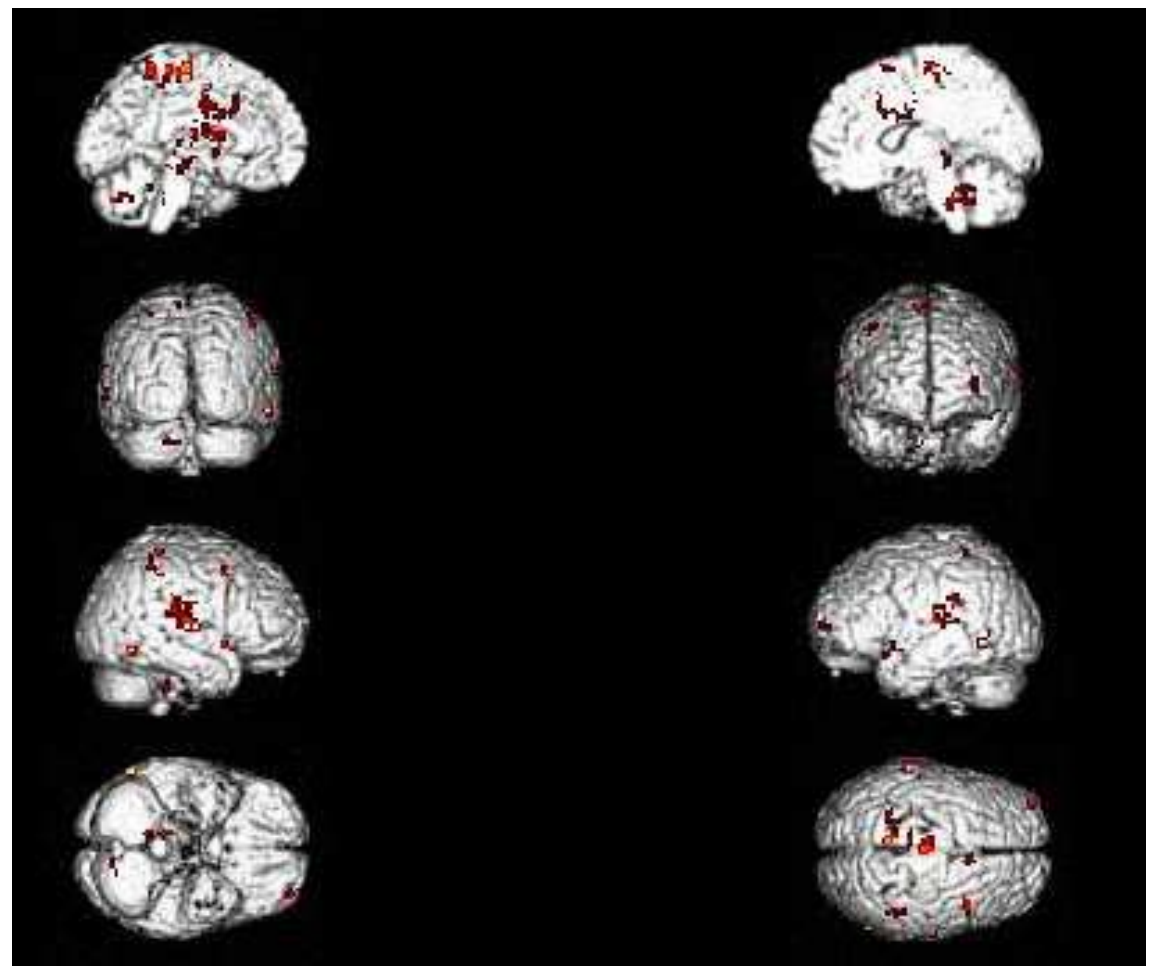

Fig. 2. Brain areas activated (coloured areas) during transcutaneous electric stimulation on the acupoints of ST36 and ST39 in the right leg $(\mathrm{P}<0.005)$.

During the manual acupuncture task, significant activation was detected only in the area of the contralateral gyrus occipitalis medius (Gom, BA19) (Table 2 and Figure 3).

\begin{tabular}{lccccccccc}
\hline Activated & Brodmann & \multicolumn{2}{c}{ Contralateral $(\mathrm{mm})$} & T value & \multicolumn{2}{c}{ Ipsilateral $(\mathrm{mm})$} & T value \\
Area & & $\mathrm{x}$ & $\mathrm{y}$ & $\mathrm{z}$ & & $\mathrm{x}$ & $\mathrm{y}$ & $\mathrm{z}$ & \\
\hline Gom & 19 & -51 & -69 & -12 & 5.55 & $/$ & $/$ & $/$ & $/$ \\
\hline
\end{tabular}

Table 2. Montreal Neurology Institute (MNI) coordinates of local maxima of cortical clusters showing significant $(\mathrm{P}<0.005)$ activity associated with manual acupuncture at the acupoints of ST36 and ST39 in the right leg. 


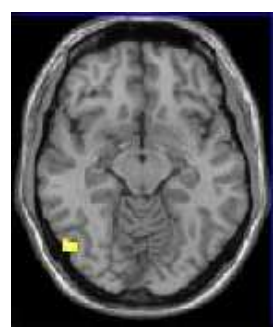

$Z=-12$

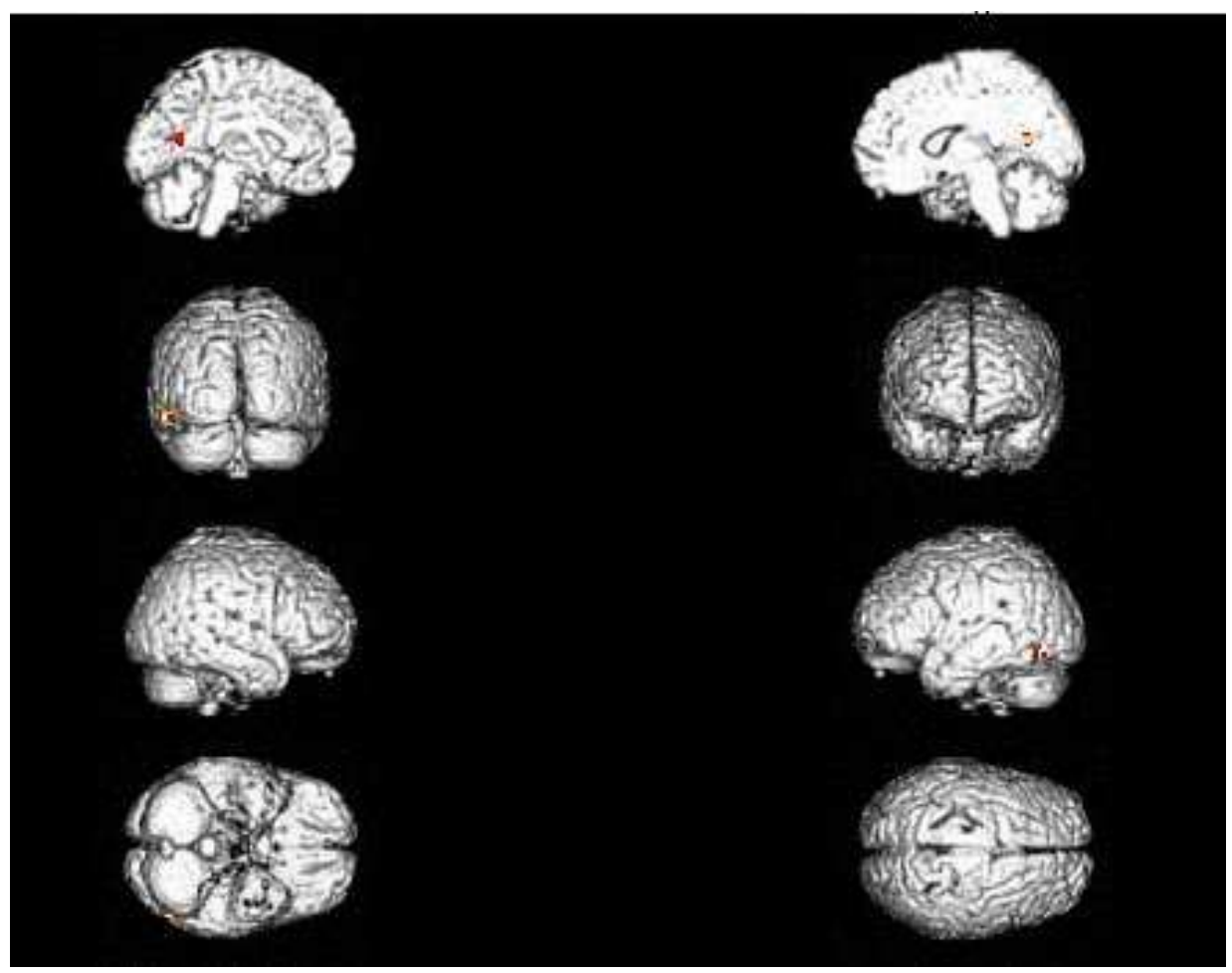

Fig. 3. Brain areas activated (coloured areas) during manual acupuncture on the acupoints ST36 and ST39 in the right leg $(\mathrm{P}<0.005)$.

During the electroacupuncture task, significant activation was identified in the areas of bilateral gyrus frontalis superior (GFs, BA6), gyrus frontalis medius (GFm, BA6,10,46), gyrus frontalis inferior (GFi, BA44-47), gyrus frontalis medialis (GFd, BA6,8), gyrus postcentralis (GPOC, BA40), lobulus parietalis inferior (LPi, BA40), precuneus (PCU, BA7), nucleus lentiformis (NL), insula (INS, BA13), gyrus cinguli (GC, BA 24,32), cerebellum (Cb) and brain stem; ipsilateral thalamus (TH) and cuneus (CU, BA18); and contralateral gyrus parahippocampalis (GH, BA35) and gyrus precentralis (GPRC, BA4) (Table 3, Figure 4). 
Acupuncture - Concepts and Physiology

\begin{tabular}{lccccccccc}
\hline Activated & Brodmann & \multicolumn{2}{c}{ Contralateral $(\mathrm{mm})$} & T value & \multicolumn{2}{c}{ Ipsilateral(mm) } & T value \\
Area & & $\mathrm{x}$ & $\mathrm{y}$ & $\mathrm{z}$ & & $\mathrm{x}$ & $\mathrm{y}$ & $\mathrm{z}$ & \\
\hline GPOC & 40 & -66 & -24 & 21 & 6.69 & 60 & -24 & 21 & 11.52 \\
GFd & 6,8 & -3 & -21 & 57 & 9.17 & 6 & 27 & 51 & 5.80 \\
GFm & $6,10,46$ & -36 & 48 & 9 & 10.87 & 45 & 39 & 24 & 13.27 \\
GFi & $44,45,46,47$ & -39 & 33 & 9 & 12.40 & 33 & 24 & 0 & 4.69 \\
GC & 24,32 & -3 & 0 & 39 & 9.67 & 6 & 39 & 12 & 6.54 \\
Brainstem & $/$ & -3 & -24 & -30 & 5.52 & 3 & -18 & -27 & 6.56 \\
GTS & 22,42 & -60 & -21 & 12 & 6.12 & 66 & -27 & 15 & 9.69 \\
GL & 18 & -18 & -102 & -15 & 6.00 & 9 & -93 & -9 & 6.58 \\
PCU & 7 & -18 & -54 & 57 & 3.91 & 18 & -54 & 54 & 6.85 \\
LPi & 40 & -57 & -39 & 45 & 5.85 & 48 & -45 & 54 & 7.79 \\
NL & $/$ & -24 & -12 & 0 & 5.96 & 15 & 3 & -3 & 7.09 \\
INS & 13 & -39 & 9 & 0 & 3.83 & 39 & 9 & 6 & 4.56 \\
U & 28,36 & -27 & -3 & -39 & 4.91 & 33 & 6 & -24 & 5.64 \\
GFs & 6,8 & -12 & 24 & 57 & 5.38 & 6 & 21 & 57 & 7.20 \\
Cb & $/$ & -9 & -72 & -33 & 7.52 & 6 & -60 & -9 & 5.85 \\
TH & $/$ & $/$ & $/$ & $/$ & $/$ & 9 & -15 & 0 & 11.83 \\
GTm & 21 & $/$ & $/$ & $/$ & $/$ & 57 & -54 & -12 & 9.14 \\
CU & 18 & $/$ & $/$ & $/$ & $/$ & 6 & -93 & 6 & 8.54 \\
GPRC & 4 & -39 & -3 & 39 & 5.87 & $/$ & $/$ & $/$ & $/$ \\
GH & 35 & -27 & 0 & -30 & 7.11 & $/$ & $/$ & $/$ & $/$ \\
IC & $/$ & -33 & -24 & 3 & 7.97 & $/$ & $/$ & $/$ & $/$ \\
\hline
\end{tabular}

Table 3. Montreal Neurology Institute (MNI) coordinates of local maxima of cortical clusters showing significant $(\mathrm{P}<0.005)$ activity associated with electroacupuncture at the acupoints of ST36 and ST39 in the right leg.
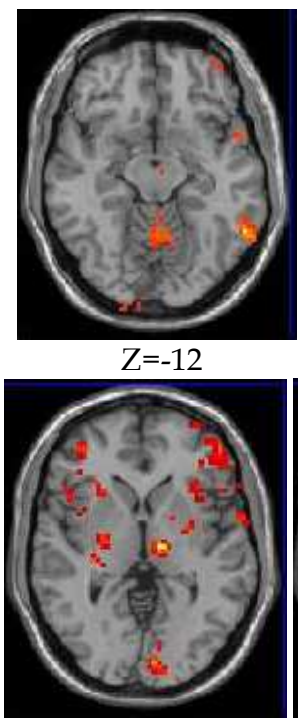

$\mathrm{Z}=0$

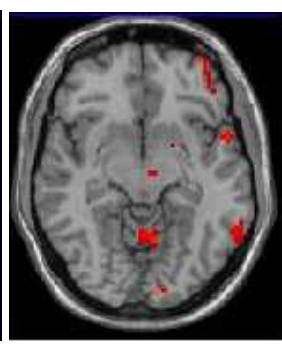

$Z=-9$

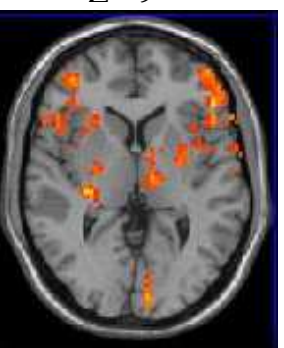

$\mathrm{Z}=3$

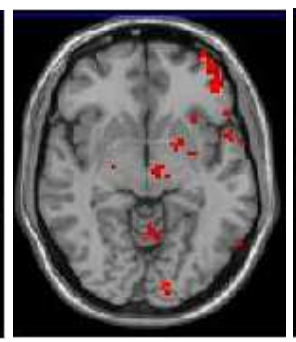

$Z=-6$

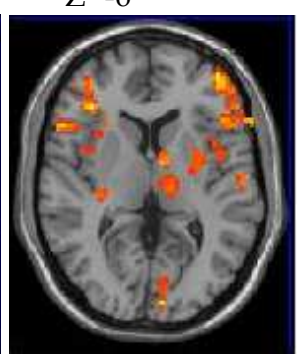

$\mathrm{Z}=6$

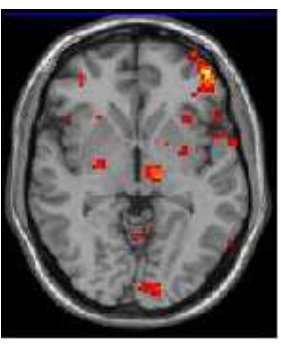

$Z=-3$

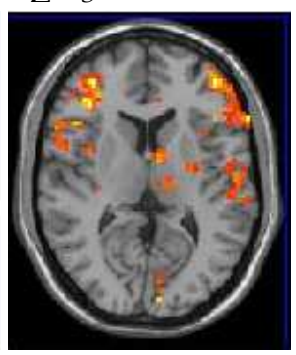

$Z=9$

(Figure 4) 
An fMRI Investigation on Brain Activity in Response to Unilateral Acupuncture,

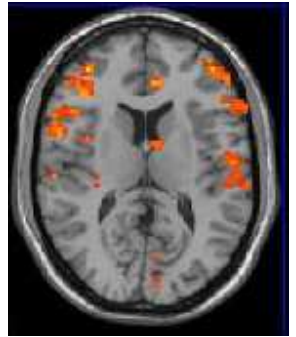

$Z=12$

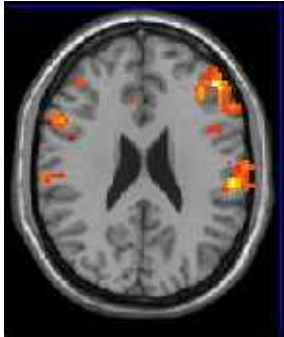

$Z=24$

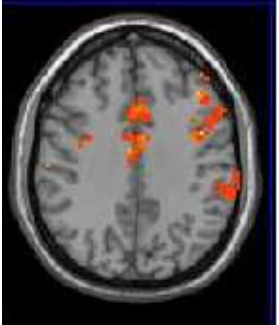

$Z=36$

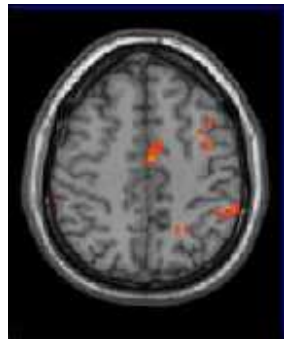

$Z=48$

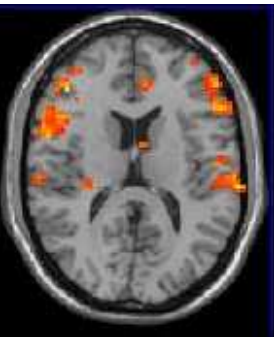

$Z=15$

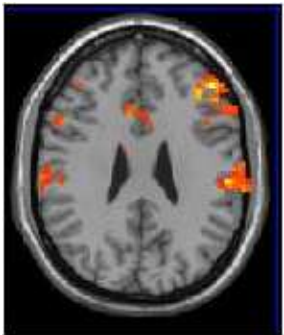

$Z=27$

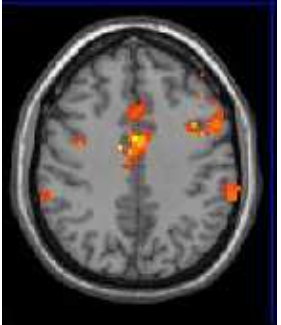

$Z=39$

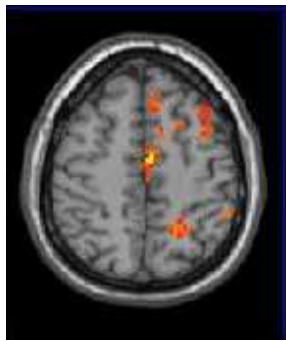

$Z=51$

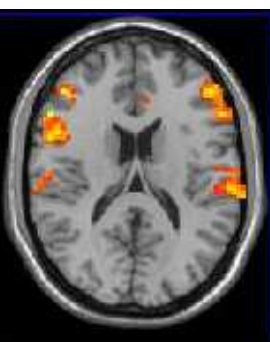

$\mathrm{Z}=18$

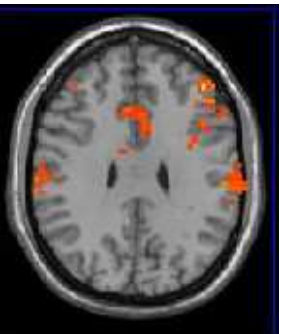

$Z=30$

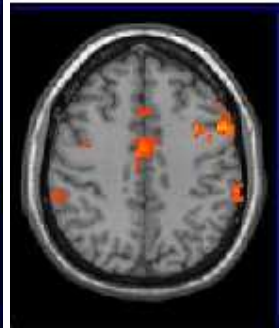

$Z=42$

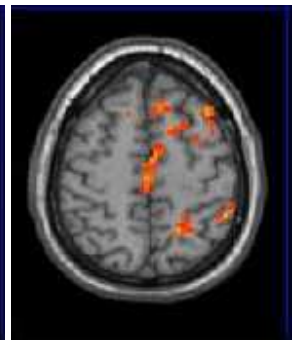

$Z=54$

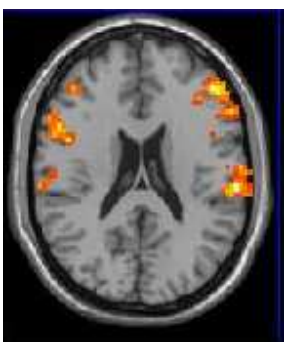

$Z=21$

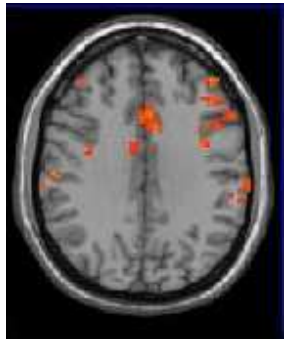

$Z=33$

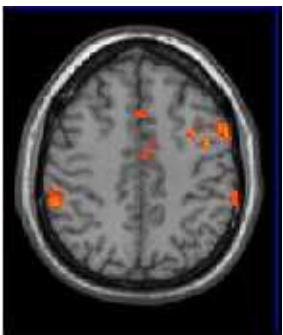

$Z=45$

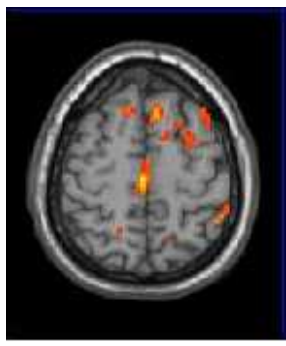

$Z=57$

(Figure 4 continuing) 


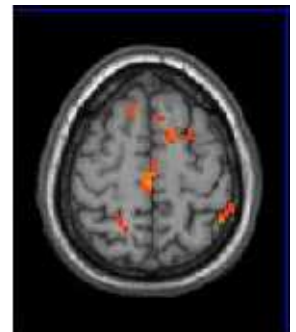

$Z=60$

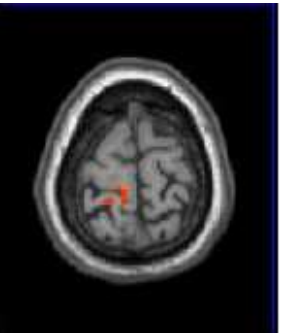

$Z=72$

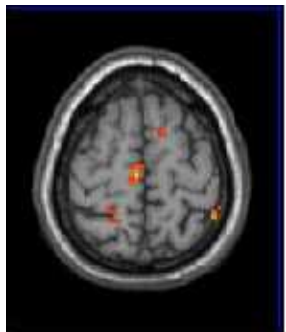

$Z=63$

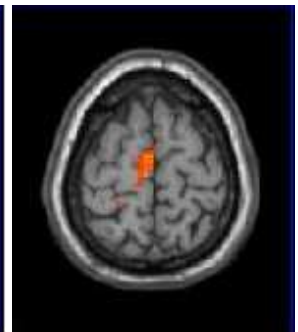

$Z=66$

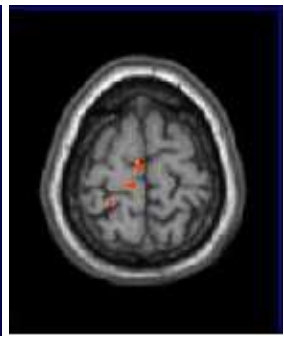

$Z=69$
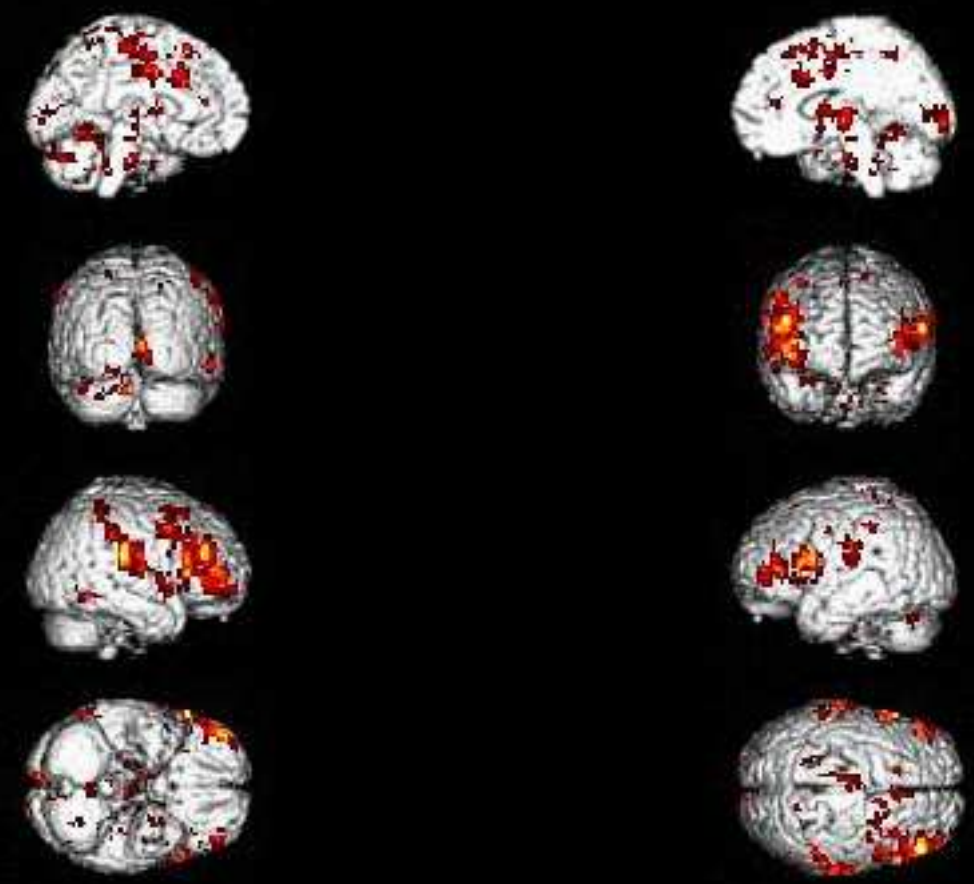

Fig. 4. Brain areas activated (coloured areas) during electroacupuncture on the acupoints of ST36 and ST39 in the right leg $(\mathrm{P}<0.005)$. 


\section{Discussion}

The results of present study demonstrated significant changes of BOLD signals in multiple brain areas during the tasks of unilateral transcutaneous electric stimulation and electroacupuncture on the acupoints of ST36 and ST39 (Table 1 and 3, Figure 2 and 4). In contrast, significantly activity was observed only in one area during the manual acupuncture task (Table 2 and Figure 3).

The present findings on the fMRI changes in response to electric stimulation appear to be in line with the information obtained from other studies. There have been reports that unilateral electric stimulation to upper limb muscles (wrist extensors and flexors) caused increased BOLD signals in the bilateral secondary somatosensory cortex, the supplementary motor area and anterior cingulate cortex; contralateral primary motor cortex, primary somatosensory cortex and premotor cortex; and the ipsilateral cerebellum (Blickenstorfer et al., 2009; Han et al., 2003). In respect of lower limb muscles, Francis and associates compared BOLD signals during unilateral active and passive dorsiflexion movement, and electric stimulation-induced dorsiflexion, and reported that the electric stimulation induced greater brain activities than passive movement, but lower activities than that induced by active movement (Francis et al., 2009). The major brain areas that showed significant activities during the electric stimulation task included bilateral dorsal and ventral premotor areas and cerebellum; and contralateral primary motor, primary sensory, secondary somatosensory areas, as well as in supplementary motor area and cingulate motor areas (Francis et al., 2009). The present results showed a similar pattern with significant activities found in the contralateral $(\mathrm{BA} 4,6,8,10)$ and bilateral $(\mathrm{BA} 8,10)$ motor-related areas and somatosensory areas (BA40) (Table 4).

\begin{tabular}{|c|c|c|c|c|}
\hline \multirow{2}{*}{$\begin{array}{l}\text { Brain area } \\
\text { (Abbreviation, Brodmann area) }\end{array}$} & \multicolumn{2}{|c|}{ Electric stimulation } & \multicolumn{2}{|c|}{ Electroacupuncture } \\
\hline & Contralat. & Ipsilat. & Contralat. & Ipsilat. \\
\hline Gyrus presentralis (GPRC, BA4) & + & & + & \\
\hline Gyrus frontalis medius (GFm, BA8,10) & + & + & + & + \\
\hline Gyrus frontalis medialis (GFd, BA6) & + & & + & + \\
\hline Gyrus frontalis superior (GFs, BA6,8) & & + & + & + \\
\hline Gyrus frontalis inferior (GFi, BA44-47) & & & + & + \\
\hline Brain stem & + & + & + & + \\
\hline Cerebellum $(\mathrm{Cb})$ & + & & + & + \\
\hline Gyrus postcentralis (GOPC, BA40) & + & + & + & + \\
\hline Lobulus parietalis inferior ( $\mathrm{LPi}, \mathrm{BA} 40)$ & + & + & + & + \\
\hline Precuneus (PCU, BA7) & & & + & + \\
\hline Nucleus lentiformis (NL) & + & & + & + \\
\hline Gyrus cinguli (GC, BA24) & + & & + & + \\
\hline Uncus (U, BA28,36) & & & + & + \\
\hline Insula (INS, BA13) & & + & + & + \\
\hline
\end{tabular}

Table 4. Comparison of brain areas that showed significant changes in fMRI signals during transcutaneous electric stimulation and electroacupuncture on acupoints of ST36 and ST39. "+" indicates a significant change in BOLD signals at $\mathrm{P}<0.005$ level.

A number of studies have also reported the effects of acupuncture and electroacupuncture on brain activities as indicated by BOLD signal changes. For example, Bai and colleagues 
reported fMRI signal changes in response to manual acupuncture at ST36 in sensorimotor cortices, bilaterally in BA9, 10, 11, 40, 44 and 45, brainstem and cerebellum; ipsilaterally in BA6; and contralaterally in BA3, etc. (Bai et al., 2009). Zhang and associates investigated the effects of electroacupuncture on acupoints of Yanglingquan (GB34) and Xuanzhong (GB39) on the left leg, and reported significantly increased brain activities bilaterally in BA4, 6, 10, 11, 18, 23 and 24, insula and cerebellum; and contralaterally in BA44 and 45, caudate, putamen and midbrain (Zhang et al., 2007). The present study also found significantly increased activities in bilateral BA6, 7, 8, 10, 13, 28, 26, 40 and 44-47, brainstem and cerebellum; and contralaterally in BA4 (Table 3 and 4). However, the manual acupuncture induced significant activity only in BA19 of the contralateral side (Table 2). The lack of significant changes in BOLD signals compared with other reports might be related to the higher threshold (10 voxels vs 3 voxels used in Bai et al., 2009) and alpha level (0.005 vs 0.05 or 0.01 used in Zhang et al., 2007) used in this study. Another possible reason could be that only the twirling manipulation of the needles was used during the experiment without the use of lifting and thrusting techniques. Therefore, the stimulation might not be strong enough to produce wider activations in the brain.

Electric stimulation has been widely used as a supplementary training method for improving muscular strength and fitness as well as a means of rehabilitation (Maffiuletti, 2010; Paillard, 2008). Electroacupuncture has recently been shown to be able to improve muscle strength as well (Huang et al., 2007). Although the electric stimulation and electroacupuncture can directly activate peripheral nerve and muscle fibres and by-pass the central nervous system, recent evidence has suggested that the training/therapeutic effects of electric stimulation may also include neural plasticity (Chae et al., 2008; Maffiuletti, 2010; Wolpaw, 2007). The current results provide new evidence about the cortical responses by comparison of the BOLD signal changes during electroacupuncture and electric stimulation. It was interesting to find that there were common bilateral activations during electric stimulation and electroacupuncture tasks in the somatosensory areas (GPOC and LPi) and secondary motor areas (GFm) that are known to be associated with somatosensory inputs processing and motor preparation, motor program encoding and sensorimotor integration (Table 4). Furthermore, electroacupuncture induced much wider bilateral brain activation than surface electric stimulation and manual acupuncture.

In the present study, the stimulation intensity utilised in the electric stimulation and electroacupuncture task was limited by participants' tolerance to the discomfort and pain. Obviously, a common factor in these two treatments was the nociceptive afferents. Pain (from nociceptors) has been shown to elicit activation of the sensorimotor cortices, rostral anterior cingulate cortex, insula, cerebellum, hippocampus and brain stem (Hui et al., 2005; Hui et al., 2009; Kong et al., 2007; Lewith et al., 2005; Seidler et al., 2004) through spinothalamus bundle. A number of cortical areas have been shown to be involved in pain processing, including the primary somatosensory cortex, the secondary somatosensory cortex, the insula, the anterior cingulate, the prefrontal cortex, the hypothalamus and periaqueductal gray (PAG) (Kong et al., 2009; Zhang et al., 2004). The primary and secondary somatosensory cortices are involved in the sensory discriminative aspect of pain processing (Liu et al., 2010), such as intensity determination and location of nociceptive stimulation (Tracey, 2005), as components of the sensory (pain) network (Wager, 2005). Afferent inputs have shown to alter the excitability of motoneurons and interneurons that affects the contralateral limb at the spinal (Robinson et al., 1979) or higher levels in the central nervous system (Hortobagyi et al., 2003; Kaelin-Lang et al., 2002). Therefore, it is 
speculated that the nociceptive inputs, together with other somatosensory afferents, may play an important role in mediating neural plasticity in adaptation to unilateral electric stimulation training and electroacupuncture. However, changes in fMRI signals observed in this study can only provide neuroanatomical evidence for the brain areas involved in the prescribed tasks and cannot provide direct evidence for the functional links between these cortical areas. How the sensory afferents affect motor function that results in improved expression of muscular strength requires further investigations.

An interesting finding of the present study is that the electroacupuncture induced a much wider cortical activation than the surface electric stimulation at the two acupoints. One possible explanation is that acupuncture required insertion of a needle into the muscle and manipulation of the needle to induce the sensation of de qi. The de qi sensation reported by the participants included aching, soreness and pressure, tingling, numbness, dull pain, heaviness, warmth, fullness and coolness without sharp pain. The complex sensations in de qi suggest involvement of a wide spectrum of myelinated and unmyelinated nerve fibers, particularly the slower conducting fibers in the tendinomuscular layers (Hui et al., 2007). In addition of de qi, electric pulses were delivered to the needle.

Whether the wider cortical responses observed in the electroacupuncture task compared with the surface electric stimulation task indicates the unique treatment effect of inserting needle at the acupoint would be an interesting question. There has been a study on rats that compared the effects of acupuncture or electroacupunture at different depth (sham acupuncture), and with (true electroacupuncture) or without electric current (sham electroacupuncture) (Chiu et al., 2003). The results of the study showed that there was no neural activation caused by the sham acupuncture. The sham electroacupuncture only induced a slight increase in brain activity in the hypothalamus; however, true electroacupuncture elicited enhanced hypothalamus response (Chiu et al., 2003). The results suggested that electroacupuncture at the acupoint produce greater activation of the central nervous system. However, one limitation of using animal models to investigate the effects of acupuncture is that no de qi sensation can be substantiated as that observed in humans. It has been suggested that transcutaneous electric stimulation should make no difference as compared with electroacupuncture on the identified points in respect of pain control (Han, 1997). However, the present results indicate there are differences between the cortical responses to the surface and needle stimulation at the given acupoints.

It has been reported that the increases of BOLD signal in secondary somatosensory area and insula were the most consistently observed regardless of acupoints or acupuncture modes (Kong et al., 2007). The insula is purported to process sensory/discriminative, rather than affective information (Craig et al., 2000; Napadow et al., 2005). Recent studies showed that insula is widely connected with cortex, subcortex and brainstem structures and is involved in decision making and subsequent behavior emotional experience and pain-related modulation. The fMRI imaging data also indicated that insula played an important role in a dynamic switching between the central-executive network and the default mode network (Liu et al., 2010; Sridharan et al., 2008). The posterior middle cingulate cortex, receiving information from insula, appeared to be important in coding acupuncture sensation intensity, then interacting with the posterolateral parietal cortex in orienting the body in response to somatosensory stimuli (Vogt, 2005). Recently, a functional imaging study also suggested a central role for the precuneus in a wide spectrum of highly integrated tasks (Hsieh et al., 2010). Based on these reports and present findings, we speculate that these 
structures may be responsible for integration of the sensory inputs associated with pain and proprioceptors, and the motor cortices for manifestation of cross education.

In summary, the present results showed that the electroacupuncture induced a much wider activation of brain areas bilaterally than that induced by the transcutaneous electric stimulation over the same acupoints, as indicated by the BOLD signal changes. Therefore the outcomes of the study did not fully support the hypotheses that electroacupuncture and surface electric stimulation at the same areas would induce similar level of activities in the brain; and that manual acupuncture at the same acupoints may also cause activation of the same regions in the brain.

\section{Conclusion}

The results of this study indicated that the unilateral electroacupunture task induced a wider bilateral activation in the brain than that induced by the unilateral transcutaneous electric stimulation at the acupoints of ST36 and ST39, although the electrical current utilised in the electroacupuncture was lower. The manual acupuncture did not induce a sufficient level of activation in the brain, as indicated by the BOLD signals, possibly due to the high threshold for identifying activation and the needle handling technique used in the study. Although the bilateral brain activities as indicated by the BOLD signals cannot directly explain the functional changes in adaptation to unilateral interventions, this study has provided new evidence for the differences between the effects of the three treatments.

\section{Acknowledgment}

This project was supported by Tianjin Scientific Research Foundation (No. 05YFGDSF02100). The researchers appreciate the guidance on acupuncture given by Dr Qing-Wen Li, and the contributions from Jian-Zhong Yin and Li-Hua Liu from the Medical Imaging Department of the Tianjin First Central Hospital to fMRI data collection. We also would like to express our thanks to Professor Yu-Feng Zang from the Cognitive Institute of Beijing Normal University for his advice on data analysis.

\section{References}

Bai, L.; Qin, W.; Tian, J.; Liu, P.; Li, L.; Chen, P.; Dai, J.; Craggs, J.G.; von Deneen, K.M. \& Liu, Y. (2009). Time-varied characteristics of acupuncture effects in fMRI studies. Human Brain Mapping, Vol.30, No.1, (November 2009), pp. 3445-3460, ISSN 10970193

Beijing College of Traditional Chinese Medicine, Shanghai College of Traditional Chinese Medicine, Nanjin College of Traditional Chinese Medicine \& The Acupuncture Institute of the Academy of Traditional Chinese Medicine (1980). Essentials of Chinese Acupuncture (1 ed.). Foreign Languages Press, ISBN 7119002406, Beijing, China

Bezerra, P.; Zhou, S.; Crowley, Z.; Brooks, L. \& Hooper, A. (2009). Effects of unilateral electromyostimulation superimposed on voluntary training on strength and crosssectional area. Muscle \& Nerve, Vol.40, No.3, (September 2009), pp. 430-437, ISSN 0148-639X 
Blickenstorfer, A.; Kleiser, R.; Keller, T.; Keisker, B.; Meyer, M.; Riener, R. \& Kollias, S. (2009). Cortical and subcortical correlates of functional electrical stimulation of wrist extensor and flexor muscles revealed by fMRI. Human Brain Mapping, Vol.30, No.3, pp. 963-975, ISSN 1097-0193

Cabric, M.; Appell, H.J. (1987). Effect of electrical stimulation of high and low frequency on maximum isometric force and some morphological characteristics in men. International Journal of Sports Medicine, Vol.8, No.4, (August 1987), pp. 256-260, ISSN $0172-4622$

Carroll, T.J.; Herbert, R.D.; Munn, J.; Lee, M. \& Gandevia, S.C. (2006). Contralateral effects of unilateral strength training: evidence and possible mechanisms. Journal of Applied Physiology, Vol.101, No.5, (November 2006), pp. 1514-1522, ISSN 8750-7587

Chae, J.; Sheffler, L. \& Knutson, J. (2008). Neuromuscular electrical stimulation for motor restoration in hemiplegia. Topics In Stroke Rehabilitation, Vol.15, No.5, pp. 412-426, ISSN 1074-9357

Chiu, J.H.; Chung, M.S.; Cheng, H.C.; Yeh, T.C.; Hsieh, J.C.; Chang, C.Y.; Kuo, W.Y.; Cheng, H. \& Ho, L.T. (2003). Different central manifestations in response to electroacupuncture at analgesic and nonanalgesic acupoints in rats: a manganeseenhanced functional magnetic resonance imaging study. Canadian Journal of Veterinary Research, Vol.67, No.2, (May 2003), pp. 94-101, ISSN 0830-9000

Craig, A.D.; Chen, K.; Bandy, D. \& Reiman, E.M. (2000). Thermosensory activation of insular cortex. Nature Neuroscience, Vol.3, No.2, (February 2000), pp. 184-190, ISSN 10976256

Dragert, K. \& Zehr, E.P. (2011). Bilateral neuromuscular plasticity from unilateral training of the ankle dorsiflexors. Experimental Brain Research, Vol.208, No.2, pp. 217-227, ISSN 1432-1106

Everaert, D.G.; Thompson, A.K.; Chong, S.L. \& Stein, R.B. (2010). Does functional electrical stimulation for foot drop strengthen corticospinal connections. Neurorehabilitation and Neural Repair, Vol.24, No.2, (February 2010), pp. 168-177, ISSN 1552-6844

Farthing, J.P. (2009). Cross-education of strength depends on limb dominance: implications for theory and application. Exercise and Sport Sciences Reviews, Vol.37, No.4, (October 2009), pp. 179-187, ISSN 1538-3008

Farthing, J.P.; Krentz, J.R. \& Magnus, C.R.A. (2009). Strength training the free limb attenuates strength loss during unilateral immobilization. Journal of Applied Physiology, Vol.106, No.3, pp. 830-836, ISSN 8750-7587

Francis, S.; Lin, X.; Aboushoushah, S.; White, T.P.; Phillips, M.; Bowtell, R. \& Constantinescu, C.S. (2009). fMRI analysis of active, passive and electrically stimulated ankle dorsiflexion. Neuroimage, Vol.44, No.2, (January 2009), pp. 469-479, ISSN 1095-9572

Han, B.S.; Jang, S.H.; Chang, Y.; Byun, W.M.; Lim, S.K. \& Kang, D.S. (2003). Functional magnetic resonance image finding of cortical activation by neuromuscular electrical stimulation on wrist extensor muscles. American Journal of Physical Medicine $\mathcal{E}$ Rehabilitation, Vol.82, No.1, pp. 17-20, ISSN 0894-9115

Han, J.S. (1997). Physiology of acupuncture: review of thirty years of research. The Journal of Alternative and Complementary Medicine, Vol.3, No.Suppl. 1, pp. S101-S108, ISSN 1075-5535 
Hortobagyi, T. (2005). Cross education and the human central nervous system. IEEE Engineering in Medicine and Biology Magazine, Vol.24, No.1, (January 2005), pp. 22-28, ISSN 0739-5175

Hortobágyi, T.; Richardson, S.P.; Lomarev, M.; Shamim, E.; Meunier, S.; Russman, H.; Dang, N. \& Hallett, M.. (2011). Interhemispheric plasticity in humans. Medicine and Science in Sports and Exercise. DOI: 10.1249/MSS.0b013e31820a94b, ISSN 0195-9131

Hortobagyi, T.; Scott, K.; Lambert, J.; Hamilton, G. \& Tracy, J. (1999). Cross-education of muscle strength is greater with stimulated than voluntary contractions. Motor Control, Vol.3, No.2, (April 1999), pp. 205-219, ISSN 1087-1640

Hortobagyi, T.; Taylor, J.L.; Petersen, N.T.; Russell, G. \& Gandevia, S.C. (2003). Changes in segmental and motor cortical output with contralateral muscle contractions and altered sensory inputs in humans. Journal of Neurophysiology, Vol.90, No.4, (October 2003), pp. 2451-2459, ISSN 0022-3077

Hsieh, C.W.; Wu, J.H.; Hsieh, C.H.; Wang, Q.F. \& Chen, J.H. (2010). Different brain network activations induced by modulation and nonmodulation laser acupuncture. Evidence-Based Complementary and Alternative Medicine, DOI: 10.1155/2011/951258, ISSN 1741-4288

Huang, L.P.; Zhou, S.; Lu, Z.; Tian, Q.; Li, X.; Cao, L.J.; Yu, J. H. \& Wang, H. (2007). Bilateral effect of unilateral electroacupuncture on muscle strength. Journal of Alternative and Complementary Medicine, Vol.13, No.5, (June 2007), pp. 539-546, ISSN 1075-5535.

Hui, K.K.S.; Liu, J.; Marina, O.; Napadow, V.; Haselgrove, C.; Kwong, K.K.; Kennedy, D.N. \& Makris, N. (2005). The integrated response of the human cerebro-cerebellar and limbic systems to acupuncture stimulation at ST 36 as evidenced by fMRI. Neuroimage, Vol.27, No.3, (September 2005), pp. 479-496, ISSN 1053-8119

Hui, K.K.S.; Nixon, E.E.; Vangel, M.G.; Liu, J.;Marina, O.; Napadow, V.; Hodge, S.M.; Rosen, B.R.; Makris, N. \& Kennedy, D.N. (2007). Characterization of the "deqi" response in acupuncture. BMC Complementary and Alternative Medicine, Vol.7, No.7, (October 2007), pp. 33, 16 pages, ISSN 1472-6882

Hui, K.K.S.; Marina, O.; Claunch, J.D.; Nixon, E.E.; Fang, J.; Liu, J.; Li, M.; Napadow,V.; Vangel, M.; Makris, N.; Chan, S.; Kwong, K.K. \& Rosen, B.R. (2009). Acupuncture mobilizes the brain's default mode and its anti-correlated network in healthy subjects. Brain research, Vol.1287, No., (September 2009), pp. 84-103, ISSN 18726240

Kaelin-Lang, A.; Luft, A.R.; Sawaki, L; Burstein, A.H.; Sohn, Y.H. \& Cohen, L.G. (2002). Modulation of human corticomotor excitability by somatosensory input. Journal of Physiology, Vol.540, No.Pt 2, (April 2002), pp. 623-633, ISSN 0022-3751

Kim, M.K.; Choi, T.Y.; Lee, M.S.; Lee, H. \& Han, C.H. (2010). Contralateral acupuncture versus ipsilateral acupuncture in the rehabilitation of post-stroke hemiplegic patients: a systematic review. BMC Complementary and Alternative Medicine, Vol.10, pp. 41, 8 pages, ISSN 1472-6882

Kong, J.; Gollub, R.L.; Webb, J.M.; Kong, J.T.; Vangel, M.G. \& Kwong, K. (2007). Test-retest study of fMRI signal change evoked by electroacupuncture stimulation. NeuroImage, Vol.34, No.3, (February 2007), pp. 1171-1181, ISSN 1053-8119

Kong, J.; Kaptchuk, T.J.; Polich, G.; Kirsch, I.V.; Vangel, M.; Zyloney, C.; Rosen, B. \& Gollub, R. (2009). An fMRI study on the interaction and dissociation between expectation of 
pain relief and acupuncture treatment. NeuroImage, Vol.47, No.3 (September 2009), pp. 1066-1076, ISSN 1095-9572

Lee, M. \& Carroll, T.J. (2007) Cross education: possible mechanisms for the contralateral effects of unilateral resistance training. Sports Medicine, Vol.37, No.1, (January 2007), pp. 1-14, ISSN 0112-1642

Lee, M.; Hinder, M.R.; Gandevia, S.C. \& Carroll, T.J. (2010). The ipsilateral motor cortex contributes to cross-limb transfer of performance gains after ballistic motor practice. Journal of Physiology, Vol.588, No.Pt 1, (January 2010), pp. 201-212, ISSN 1469-7793

Lewith, G.T.; White, P.J. \& Pariente, J. (2005). Investigating acupuncture using brain imaging techniques: the current state of play. Evidence-Based Complementary and Alternative Medicine, Vol.2, No.3, (September 2005), pp. 315-319, ISSN 1741-427X

Li, X.T. (1983). Handedness in Chinese. Acta Psychologica Sinica, Vol.15, No.3, (March 1983), pp. 27-35. ISSN 0439-755X

Lin, Y.P. \& Pan, L. (2004). Current research on Juci. Journal of Yun Nan Chinese Medicine, Vol.25, No.5, (May 2004), pp. 41-43, ISSN 1007-2349

Liu, P.; Zhou, G.; Zhang, Y.; Dong, M.; Qin, W.; Yuan, K.; Sun, J.; Liu, J.; Liang, J.; von Deneen, K.M.; Liu, Y. \& Tian, J. (2010). The hybrid GLM-ICA investigation on the neural mechanism of acupoint ST36: an fMRI study. Neuroscience Letters, Vol.479, No.3, (August 2010), pp.267-271, ISSN 1872-7972

Maffiuletti, N.A. (2010). Physiological and methodological considerations for the use of neuromuscular electrical stimulation. European Journal Of Applied Physiology, Vol.110, No.2, pp. 223-234, ISSN 1439-6327

Munn, J.; Herbert, R.D. \& Gandevia, S.C. (2004). Contralateral effects of unilateral resistance training: a meta-analysis. Journal of Applied Physiology, Vol.96, No.5, (May 2004), pp. 1861-1866, ISSN 8750-7587

Napadow, V.; Makris, N.; Liu, J.; Kettner, N.W.; Kwong, K.K. \& Hui, K.K.S. (2005). Effects of electroacupuncture versus manual acupuncture on the human brain as measured by fMRI. Human Brain Mapping, Vol.24, No.3, (March 2004), pp. 193-205, ISSN 10659471

Paillard, T. (2008). Combined application of neuromuscular electrical stimulation and voluntary muscular contractions. Sports Medicine, Vol.38, No.2, pp. 161-177, ISSN 0112-1642

Robinson, K.L.; Mcllwain, J.S. \& Hayes, K.C. (1979). Effects of H-reflex conditioning upon the contralateral alpha motoneuron pool. Electroencephalography and Clinical Neurophysiology, Vol.46, No.1, (January 1979), pp. 65-71, ISSN 0013-4694

Seidler, R.D.; Noll, D.C. \& Thiers, G. (2004). Feedforward and feedback processes in motor control. Neuroimage, Vol.22, No.4, (August 2004), pp. 1775-1783, ISSN 1053-8119

Singer, K. (1986). The influence of unilateral electrical muscle stimulation on motor unit activity patterns in atrophic human quadriceps. The Australian Journal of Physiotherapy, Vol.32, No.1, pp. 31-37, ISSN 0004-9514

Sridharan, D.; Levitin, D.J. \& Menon, V. (2008). A critical role for the right fronto-insular cortex in switching between central-executive and default-mode networks. Proceedings of the National Academy of Sciences, Vol.105, No.34, pp. 12569-12574, ISSN 0027-8424 
Tachino, K.; Susaki, T. \& Yamazaki, T. (1989). Effect of electro-motor stimulation on the power production of a maximally stretched muscle. Scandinavian Journal of Rehabilitation Medicine, Vol.21, No.3, (June 1989), pp. 147-150, ISSN 0036-5505

Tracey, I. (2005). Nociceptive processing in the human brain. Current Opinion in Neurobiology, Vol.15, No.4, (August 2005), pp. 478-487, ISSN 0959-4388

Vogt, B.A. (2005). Pain and emotion interactions in subregions of the cingulate gyrus. Nature Reviews Neuroscience, Vol.6, No.7, pp. 533-544, ISSN 1471-003X

Wager, T.D. (2005). The neural bases of placebo effects in pain. Current Directions in Psychological Science, Vol.14, No.4, pp. 175-179, ISSN 0963-7214

Wolpaw, J. R. (2007). Spinal cord plasticity in acquisition and maintenance of motor skills. Acta Physiologica, Vol.189, No.2, pp. 155-169, ISSN 1748-1708

Woo, Y.M.; Lee, M.S. \& Nam, Y. (2006). Effects of contralateral electroacupuncture on brain function: a double-blind, randomized, pilot clinical trial. Journal of Alternative and Complementary Medicine, Vol.12, No.8, (October 2006), pp. 813-815, ISSN 1075-5535

Zhang, J.H.; Cao, X.D.; Lie, J.; Tang, W.J.; Liu, H.Q. \& Fenga, X.Y. (2007). Neuronal specificity of needling acupoints at same meridian: a control functional magnetic resonance imaging study with electroacupuncture. Acupuncture $\mathcal{E}$ ElectroTherapeutics Research, Vol.32, No.3-4, pp. 179-193, ISSN 0360-1293

Zhang, W.T.; Jin, Z.; Luo, F.; Zhang, L.; Zang, Y.W. \& Han, J.S. (2004). Evidence from brain imaging with fMRI supporting functional specificity of acupoints in humans. Neuroscience Letters, Vol.354, No.1, (January 2004), pp. 50-53, ISSN 0304-3940.

Zhou, S. (2000). Chronic neural adaptations to unilateral exercise: mechanisms of cross education. Exercise and Sport Sciences Reviews, Vol.28, No.4, (October 2000), pp. 177184, ISSN 0091-6331

Zhou, S.; Oakman, A. \& Davie, A. (2002). Effects of unilateral voluntary and electromyostimulation training on muscular strength on the contralateral limb. The Hong Kong Journal of Sports Medicine and Sports Science, Vol.XIV, (May 2002), pp. 111, ISSN 1728-869X 


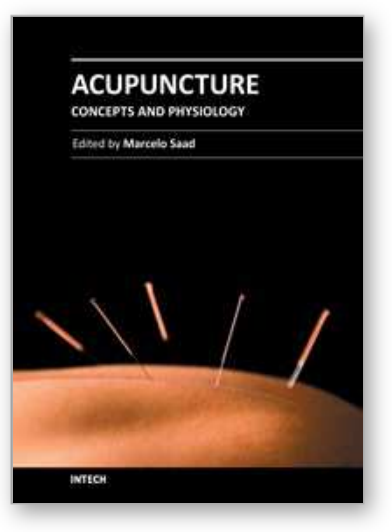

\author{
Acupuncture - Concepts and Physiology \\ Edited by Prof. Marcelo Saad
}

ISBN 978-953-307-410-8

Hard cover, 222 pages

Publisher InTech

Published online 10, October, 2011

Published in print edition October, 2011

Acupuncture and related techniques are useful tools for treating a spectrum of diseases. However, there are still many areas of controversy surrounding it. We hope this book can contribute to guide the advance of this ancient medical art. In the present work, the reader will find texts written by authors from different parts of the world. The chapters cover strategic areas to collaborate with the consolidation of the knowledge in acupuncture. The book doesnâ $\in^{\mathrm{TM}} \mathrm{t}$ intend to solve all the questions regarding this issue but the main objective is to share elements to make acupuncture more and better understood at health systems worldwide.

\title{
How to reference
}

In order to correctly reference this scholarly work, feel free to copy and paste the following:

Li-Ping Huang, Shi Zhou, Xi-Lian Hu, Xia Li, Heng Xiang, Na Xiao, Long-Jun Cao, Yong-Jun Wang and Hui Wang (2011). An fMRI Investigation on Brain Activity in Response to Unilateral Acupuncture,

Electroacupuncture and Electromyostimulation on ST36 and ST39, Acupuncture - Concepts and Physiology, Prof. Marcelo Saad (Ed.), ISBN: 978-953-307-410-8, InTech, Available from:

http://www.intechopen.com/books/acupuncture-concepts-and-physiology/an-fmri-investigation-on-brainactivity-in-response-to-unilateral-acupuncture-electroacupuncture-and

\section{INTECH}

open science | open minds

\section{InTech Europe}

University Campus STeP Ri

Slavka Krautzeka 83/A

51000 Rijeka, Croatia

Phone: +385 (51) 770447

Fax: +385 (51) 686166

www.intechopen.com

\section{InTech China}

Unit 405, Office Block, Hotel Equatorial Shanghai

No.65, Yan An Road (West), Shanghai, 200040, China 中国上海市延安西路65号上海国际贵都大饭店办公楼 405 单元

Phone: +86-21-62489820

Fax: +86-21-62489821 
(C) 2011 The Author(s). Licensee IntechOpen. This is an open access article distributed under the terms of the Creative Commons Attribution 3.0 License, which permits unrestricted use, distribution, and reproduction in any medium, provided the original work is properly cited. 